\title{
The Preparation and Electrochemical Properties of Perovskite La0.6Sro.4CoO3-d for Catalytic Reduction of Oxygen
}

\author{
Lining Fang \\ School of Chemical Engineering, Tianjin University, Tianjin 300072, China \\ E-mail: lningfang008i@ foxmail.com
}

doi: 10.20964/2017.01.07

Received: 1 October 2016 / Accepted: 17 November 2016 / Published: 12 December 2016

$\mathrm{La}_{0.6} \mathrm{Sr}_{0.4} \mathrm{CoO}_{3-\mathrm{d}}$ powder in nanoscale was produced through flame spray synthesis (FSS), which was a process method of particles in large scale. Then, the catalytic performance of the powder as a bifunctional catalyst towards oxygen evolution reaction (OER) and oxygen reduction reaction (ORR) was evaluated. The effect of this processing method on the as-prepared powders was studied through nitrogen adsorption (BET), thermal gravimetric analysis (TGA) and X-ray powder diffraction (XRD). The remarkable electrocatalytic activities were observed in all the synthesized $\mathrm{La}_{0.6} \mathrm{Sr}_{0.4} \mathrm{CoO}_{3-\mathrm{d}}$ compared with Ketjen black. Combined with the structure and electrochemical properties, a systematical study on the catalytic activity of $\mathrm{La}_{0.6} \mathrm{Sr}_{0.4} \mathrm{CoO}_{3-\mathrm{d}}$ towards both OER and ORR was carried out. Besides, the battery capacity of $\mathrm{La}_{0.6} \mathrm{Sr}_{0.4} \mathrm{CoO}_{3-\mathrm{d}}$ was investigated in a lithium-air battery as an air cathodic catalyst.

Keywords: Perovskite; Oxygen reduction reaction; Oxygen reduction reaction; Oxygen evolution reaction; Cathode

\section{FULL TEXT}

(C) 2017 The Authors. Published by ESG (www.electrochemsci.org). This article is an open access article distributed under the terms and conditions of the Creative Commons Attribution license (http://creativecommons.org/licenses/by/4.0/). 